\title{
The Analytical Review of the Condition of Unmanned Underwater Vehicles
}

\author{
A.A. Koshurina, M.S. Krasheninnikov, R.A. Dorofeev, D.M. Kurilsky and S.A. Ivanov \\ 603950, Russia, Nizhny Novgorod, Minina street, 24, NNSTU named after R.E. Alekseev
}

\begin{abstract}
The purpose of this article is the evaluation of the actual condition of unmanned underwater vehicles in the world. The extensive review of the world market of unmanned underwater vehicles was made. The all reviewed vehicles are used at present time or exist like prototypes. All robots were systematized by most important technical characteristics. In the conclusion of the article the analysis of the reviewed UUV's are presented. Based on the analysis the conclusion about actual condition of unmanned underwater vehicles was made. Also the most promising ways and tendencies of development are represented.
\end{abstract}

Keywords-unmanned underwater vehicles; group interaction; autonomy; robots

\section{INTRODUCTION}

The growing use of unmanned systems - air, surface, ground, and underwater is continually demonstrating new possibilities, that can assist naval forces maintain maritime superiority [1]. The recent progress of exploration and reclamation of the Global Ocean is caused with development of new technologies, including the development of unmanned underwater vehicles (UUV). The development of the vehicles is fast paced, despite on different difficulties. The intensive development of underwater vehicle construction is determined by increased needs of solving different tasks. The most important tasks are exploration of resources on ocean bottom, namely, oil and gas resources; development and maintaining of oil and gas fields; execution of rescue operations. The accomplishment of wide researches of the Global Ocean is needed for solving of all these tasks [2].

Manned underwater vehicles, for example, bathyscaphs are very expensive, huge and required special vessels for transportation. Also, every operation with bathyscaphs have risk for operators. Therefore, controlled unmanned underwater vehicles with cable have wide distribution. However, such vehicles have serious disadvantages. The first disadvantage is a cable, because it can limit immersion depth and operating range. Usually, cable controlled UUV are used for rescue operations and when operational control is required. However, autonomous UUV are becoming more popular. Such vehicles can carry different equipment for scientific tasks without a human-operator.

\section{THE REVIEW OF UVV}

Autonomous UUV have most practical interest, because such vehicles are not limited by a cable and have wide operational range, high maneuverability, independence of special vessels, high depth of immersion, high performance. Advances in unmanned ground vehicles have reduced human casualty risk during EOD operations. Investment in UUV technologies is considered particularly important for the maritime environment because UUVs can "get the man out of the minefield" for some, if not all, required missions [3].

Nowadays, autonomous UUV are most often used for information gathering and scouting. Also, such vehicles are used for patrolling and mine clearing operations.

Our scientific collective have made the review of unmanned underwater vehicles among various countries. More than 42 samples of such vehicles were found. Some of them was built and used and some are on the different stages of introduction (prototype, experimental sample, taken to weaponry, are using today and etc.).

UUV (Table 1) which stand out by their technical characteristics among other unmanned underwater vehicles are presented in this article. Main technical characteristics are: universality; depth of immersion; operating time; autonomy and stage of introduction.

\section{THE ANALYSIS UVV}

The analysis lets to see the distribution of UVV samples among different countries-developers (Figure 1): $23 \%$ - are developed in Russia; 33\% - USA; 11\% - UK; 6\% - Canada and $27 \%$ - European countries (Netherlands; Iceland; Norway and Scotland). Also results of the analysis show that cable controlled UVV are most often used today (Figure 2), however, there is the trend of increased usage of remote controlled autonomous UVV.

The most universal and functional UVV are:

- Bluefin-21, Bluefin Robotics Corporation, USA;

- GAVIA, Hafmynd, Iceland;

- $\quad$ Proteus, Columbia Group, USA.

The UUV with biggest immersion depth:

- Marlin, Lockheed Martin, USA;

- $\quad$ Remus 6000, Hydroid, USA.

The main advantage of UUV Proteus is the ability to move with high speed $(18 \mathrm{~km} / \mathrm{h}$ ) and carry weapon (mines and torpedoes) [4]. The payload of Proteus is $1900 \mathrm{~kg}$. No one UUV can reach such speed and payload. The underwater vehicle Remus 6000 is able to immerse for 6000 meters of 
TABLE I. THE COMPARISON TABLE OF REMOTE CONTROLLED UUV

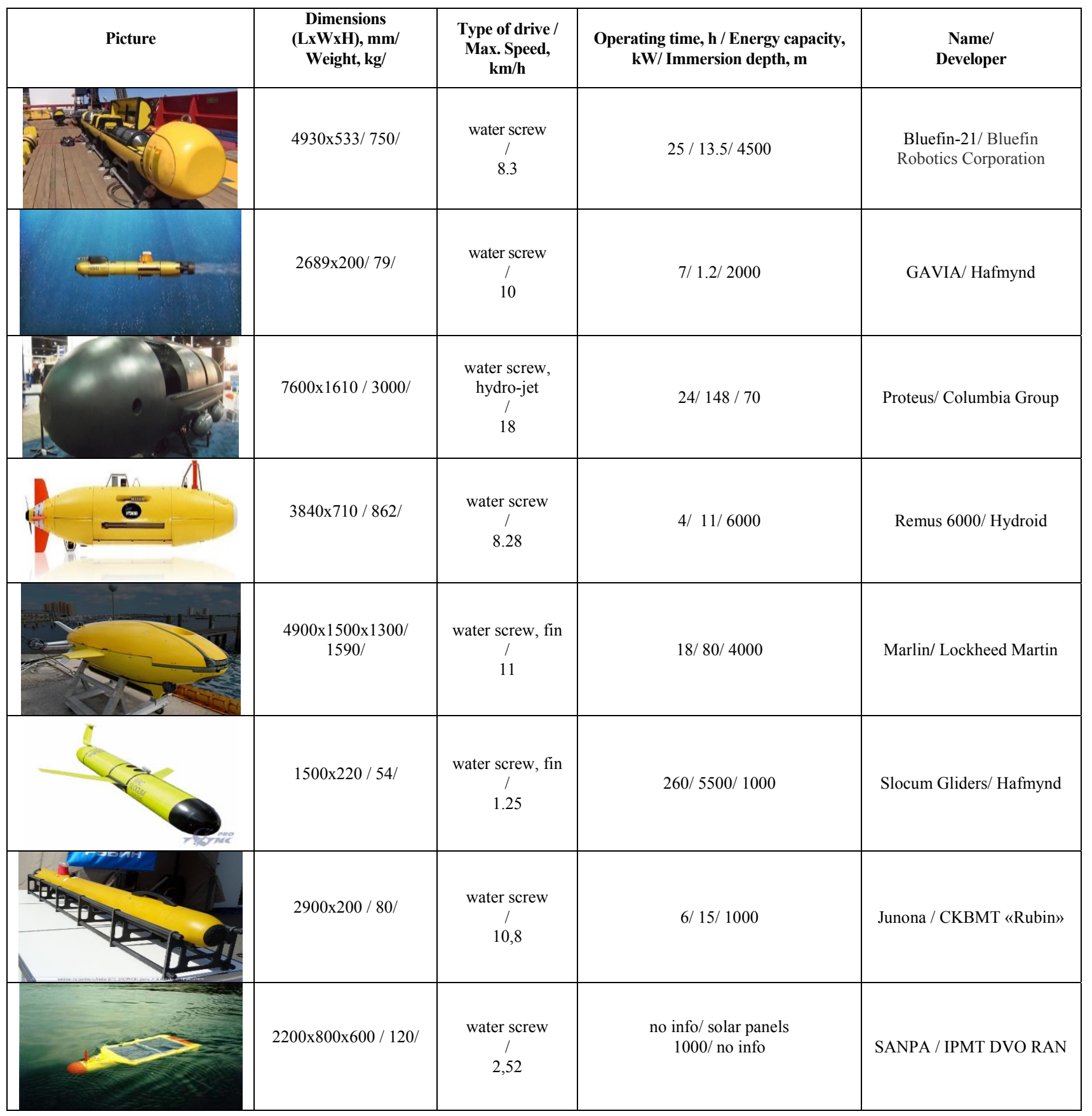




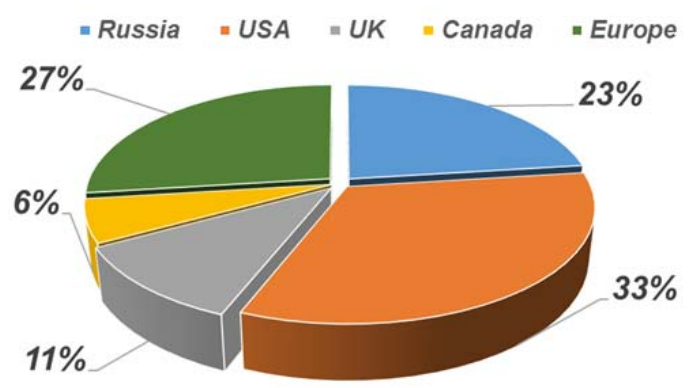

FIGURE I. COUNTRIES-DEVELOPERS OF UVV

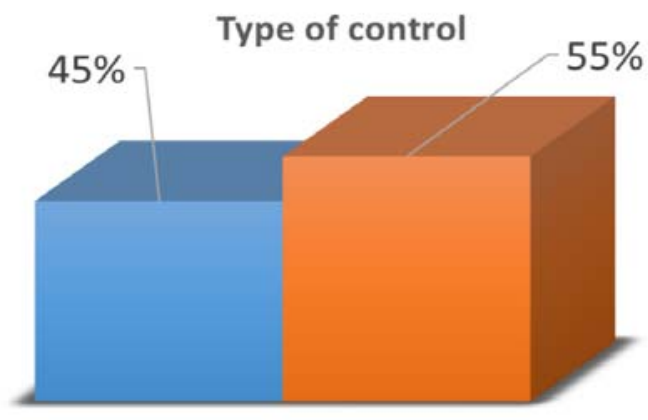

- Remote control = Cable

FIGURE II. UVV'S RANGING BY TYPE OF CONTROL

\section{DEVELOPMENT TRENDS}

UUV can be suitable for military tasks and operations, if they will be equipped with weapon. However, most UUV has torpedo form. It makes most UUV unable to be equipped by weapon or another equipment and carry enough load. Accordingly, the trend of UUV development in military way is the generation of body geometry of UUV, which can be adapted for battlefield.

For dual-purpose autonomous UUV is necessary to increase the battery life to perform special operations (scouting, information gathering and mine clearing). Herewith, it's necessary to pay attention for development of underwater listening devices, efficient batteries and usage of modern construction materials.

Another perspective trend of UUV development is introducing in this sphere technologies of group interaction. At present time, works on development of algorithms and principles of robot group interaction is extremely important object for researches [6].

Nowadays, the works on development of methods and algorithms of optimal planning for group actions of ground and surface robots is carrying out in NNSTU named after R.E. Alekseev with financial support from the government in the face of the Russian Ministry of Education under the Federal Program "Research and development on priority directions of the scientific-technological complex of Russia for 2014-2020", the unique identifier of the project: RFMEFI57414X0055.

\section{REFERENCES}

[1] Department of the Navy, "The Navy Unmanned Undersea Vehicle (UUV) Master Plan", 9 Nov 2004.

[2] Ageev M.D., Kasatkin B.A, Kiselev L.V. Automatic underwater vehicles. // L.: Sudostoenie, 1981, 224c.

[3] William P. Ervin, J. Patrick Madden, and Qeorge W. Pollitt "Unmanned Underwater Vehicle Independent Test and Evaluation”, Johns Hopkins apl technical digest, volume 32, number 5 (2014).

[4] Information on http://www.navaldrones.com/Proteus.html.

[5] Information on http://www.km.kongsberg.com/ks web/nokbg0397.nsf/AllWeb/ 9CA34097F2E3AB82C1257 4AB0044D9A2/\$file/remus6000web.pdf?OpenElement.

[6] Vasilyev, A. Koshurina, M. Krasheninnikov, E. Smirnova. Use mobile robots groups for rescue missions in extreme climatic conditions // Annals of 25th DAAAM International Symposium on Intelligent Manufacturing and Automation, DAAAM 2014. 